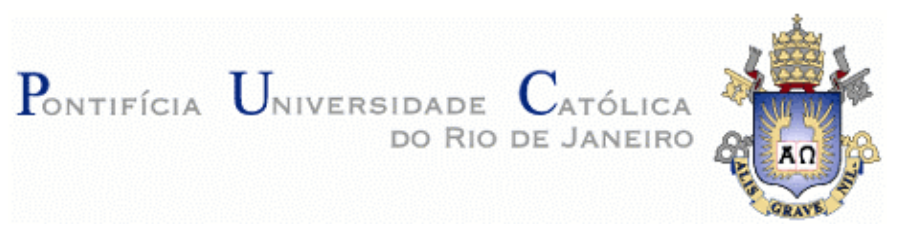

Cláudia Stamato

\title{
Modelo de Banheiro Domiciliar para Idosos: Uma Abordagem Ergonômica
}

\section{Dissertação de Mestrado}

Dissertação apresentada como requisito parcial para obtenção do grau de Mestre pelo Programa de Pós-graduação em Design, do Departamento de Artes e Design da PUC-Rio.

Orientadora: Anamaria de Moraes

Rio de Janeiro 


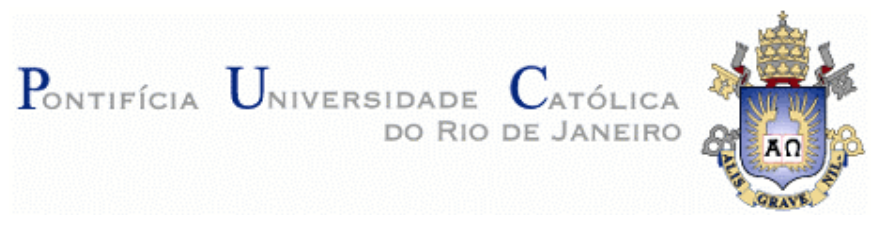

Cláudia Stamato

\section{Modelo de Banheiro Domiciliar para Idosos: Uma Abordagem Ergonômica.}

\section{Dissertação de Mestrado}

Dissertação apresentada como requisito parcial para obtenção do grau de Mestre pelo Programa de Pósgraduação em Design, do Departamento de Artes e Design da PUC-Rio. Aprovada pela Comissão Examinadora abaixo assinada

Profa. Anamaria de Moraes - PUC-Rio Orientadora/Presidente da Banca Departamento de Artes e Design - PUC-Rio

\section{Valéria Barbosa Gomes - UERJ}

Sydney Fernandes de Freitas - UERJ

Prof. Dr. Paulo Fernando Carneiro de Andrade Coordenador Setorial do Centro de Teologia e Ciências Humanas - PUC-Rio

Rio de Janeiro, 26 de Março de 2007 
Todos os direitos reservados. É proibida a reprodução total ou parcial do trabalho sem autorização da universidade, autora e da orientadora.

\section{Cláudia Stamato}

Graduou-se em Design de Produto pela Univer Cidade, em 2000. Cursou a Especialização, em nível de Pós-graduação Lato-Sensu, em Ergonomia e Usabilidade, pela PUC-Rio, em 2004. Durante o Mestrado em Design participou do Programa de Bolsa de Auxílio, "Aluno Nota 10", da

FAPERJ. É membro do Laboratório de Ergonomia da PUC-Rio, desde 2004. É professora da disciplina Planejamento Ambiental e Envelhecimento do curso de Aperfeiçoamento em Saúde do Idoso, pela UNATI / UERJ. Fez parte da Comissão Organizadora dos congressos $4^{\circ}$ e $5^{\circ}$ Ergodesign (2004 e 2005) e $3^{\circ}$ e $5^{\circ}$ USIHC (2004 e 2005). Coordenou Sessão Técnica no $6^{\circ}$ Ergodesign e na XIV Abergo - Congresso Brasileiro de Ergonomia (2006).

Ficha Catalográfica

Stamato, Cláudia

Modelo de banheiro domiciliar para idosos: uma abordagem ergonômica / Cláudia Stamato ; orientador: Anamaria de Moraes. - 2007

2 v. : il. ; $30 \mathrm{~cm}$

Dissertação (Mestrado em Artes e Design)Pontifícia Universidade Católica do Rio de Janeiro, Rio de Janeiro, 2007.

Inclui bibliografia

1. Artes - Teses. 2. Ergonomia. 3. Banheiro residencial. 4. Idosos. 5. Necessidades específicas. 6. Diretrizes antiquedas. I. Moraes, Anamaria. II. Pontifícia Universidade Católica do Rio de Janeiro. Departamento de Artes. III. Título. 
Dedico esta Dissertação, à minha tia querida, Marlene Vasquez Pereira de Mello, que sempre valorizou o conhecimento, a educação e manteve a família reunida. Deixou uma saudade interminável 


\section{Agradecimentos}

À minha preciosa mãe, Sandra Maria Stamato, que sempre me estimulou a seguir em frente, enfrentando as dificuldades da vida.

Ao meu marido José Henrique Nassif Arruda, pela compreensão e paciência com as intermináveis horas dentro da PUC e fora de casa.

À minha orientadora Preferida Anamaria de Moraes, pela sua generosidade e exigência, abundantes e constantes, que me orientaram na pesquisa e na vida.

Aos amigos Manuela Quaresma, Myrtes Raposo, Selma Lunardi, Lúcia Gomes Ribeiro, Myrian Britto e Giuseppe Amado, pelo cuidado e carinho nos primeiros momentos de uma nova realidade; pelas contribuições para o referencial teórico e principalmente pela amizade concedida.

Aos amigos Cláudio Noronha, Lílian Passos, Vera Geraldo Vilanova, Eduardo Brandão e José Guilherme Santa-Rosa, Rodrigo Peixoto Leite, Renato Casseb e Rosa Lídice Valim por colaborarem na prática na aplicação das técnicas e reforçarem os laços de amizade.

Aos funcionários amigos Romário César, Rodrigo Medeiros, Cláudio Roberto Barros, Marlon de Oliveira, Aylton Pessanha, Mônica do Nascimento, Josué Silva e Aparecido da Silva pelo auxílio constante e paciência sem fim nos trâmites burocráticos

Agradeço à FAPERJ, pelo auxílio financeiro, sem o qual teria sido impossível cursar este Mestrado. 


\section{Resumo}

Stamato, Cláudia; Moraes, Anamaria de. Modelo de banheiro Domiciliar Para Idosos - Uma Abordagem Ergonômica. Rio de Janeiro, 2007. 399p. Dissertação de Mestrado - Departamento de Artes e Design, Pontifícia Universidade Católica do Rio de Janeiro.

A dissertação Modelo de Banheiro Domiciliar para Idosos - Uma Abordagem Ergonômica, apresenta um modelo que fornece orientações para a construção de banheiros residenciais. Através de sugestões para adaptação da arquitetura interna do banheiro residencial, busca-se aqui contribuir para possibilitar a independência e autonomia dos usuários idosos durante a execução de suas tarefas de cunho íntimo. Este estudo tem como objetivo principal, contribuir para a instrução de idosos, seus familiares e geriatras; bem como contribuir para a orientação de profissionais da construção civil, com sugestões de diretrizes a serem somadas ao código de edificações da cidade do Rio de Janeiro. Foram realizadas entrevistas, tanto com idosos, quanto com geriatras, foi organizado um grupo de foco com idosos e, além disso, foram feitas apreciações ergonômicas em cinco banheiros similares de um mesmo edifício, com observações e registros fotográficos in loco, aplicação do método Corlett e de questionários visando o levantamento do perfil. Ao final foi desenvolvido um quadro do parecer ergonômico, sugerindo soluções/ recomendações preliminares para os problemas encontrados. Com o aumento contínuo da população de idosos no país, é importante que medidas preventivas sejam adotadas através da legislação e políticas públicas, a fim de oferecer a toda a população uma velhice ativa, como a Organização das Nações Unidas sugere desde 1982. Através da oferta de conforto e segurança física e psicológica a este segmento da população, bem como através do atendimento às suas necessidades específicas, pode-se alcançar o intuito da ONU.

\section{Palavras-chaves}

Ergonomia, banheiro residencial, idosos, necessidades específicas, diretrizes anti-quedas; 


\section{Abstract}

Stamato, Cláudia; Moraes, Anamaria de (Advisor) Home Toilet Model for Elderly People - An Ergonomic's Approach. Rio de Janeiro, 2007. 399p. MSc. Dissertation - Departamento de Artes e Design, Pontifícia Universidade Católica do Rio de Janeiro.

The dissertation Home Toilet Model for Elderly People - An Ergonomic's Approach, proposes a model to guide the construction of residential bathrooms. Mainly presenting suggestions to adapt the average architecture of the residential bathrooms, this document wishes to contribute to the autonomy of the elderly users at the bathroom. The primarily objective of this study is help to educate elderly people, his relatives and doctors; as well as guide professionals that work in areas related to the civil construction by adding suggestions and guidelines at the construction code of the city of Rio de Janeiro . Interviews had been carried through, as much with aged, how much with doctor geriatrics, an aged focus group was organized, moreover, ergonomic appreciations in five similar bathrooms of one same building had been made, with comments and photographic registers in I lease, application of the Corlett method and questionnaires aiming at the survey of the profile. To the end a document was developed suggesting preliminary recommendations as solutions to stop of the joined problems. With the continuous increase of the population of aged in the country, it is important that writ of prevention the legislation and public politics are adopted through in order to offer to all the population an active oldness, as the Organization of United Nations suggests since 1982. This can only occurs, through offers of comfort and physical and psychological security to this segment of the population, as well as through the attendance to its specific necessities.

\section{Key-Words}

Ergonomics, home bathroom, elderly people, specific necessities, guidelines against falls 


\section{Sumário}

Introdução 12

1.1. Tipo de Pesquisa 12

1.2. Objeto 12

1.3. Problema 13

1.4. Hipótese 13

1.5. Variáveis 14

1.6. Objetivos 14

1.7. Métodos e Técnicas $\quad 15$

1.8. Contextualização 16

1.9. Quadro de capítulos 17

2. Envelhecimento Demográfico 22

2.1. Introdução do Capítulo 2

2.2. Envelhecimento da população mundial 23

2.3. Envelhecimento da população brasileira 28

2.4. O que muda socialmente 33

2.5. O que muda economicamente 36

2.6. O que muda nas políticas públicas 38

2.7. Conclusão do Capítulo 2

2.8. Referências Bibliográficas do Capítulo 249

3. Envelhecimento Humano 50

3.1. Conceito de Envelhecimento 50

3.2. Como envelhecer com saúde 59

3.2.1. Alimentação 63

3.2.2. Atividades físicas 65

3.2.3. Exercitando a mente 67

3.2.4. O Homem é um ser social 68

3.3. Conclusão do Capítulo 3

3.4. Referências Bibliográficas do Capítulo 3 
4.1. Introdução do Capítulo 4

4.2. O valor do ancião 75

4.3. Por que as famílias não preparam a casa para 76 receber seu idoso?

4.4. Legislação em vigor / De quem é a

83

responsabilidade social? Do Governo ou da

Sociedade?

4.5. Sustentação da Previdência X Pirâmide

Invertida

4.6. Conclusão do Capítulo 4

4.7. Referências Bibliográficas do Capítulo 4

5. Fundamentação Teórica: Perfil do idoso

92 brasileiro/ carioca

5.1. Introdução do Capítulo 5 / Perfil do idoso carioca 92

5.1.1. Mortalidade da População idosa brasileira e 98 carioca

5.2. Dados estatísticos das doenças mais comuns 105 que acometem os idosos cariocas

5.2.1. Avaliação Geriátrica Global 107

5.2.2. Doenças mais comuns acometidas aos idosos 110 cariocas e seus Tratamentos

5.3. Autonomia X Dependência 123

5.3.1. Dificuldades criadas pela degeneração física 126

5.3.2. Tabela antropométrica comparativa. 132

5.4. Conclusão do Capítulo 5

5.5. Referências Bibliográficas do Capítulo 5 
6. Estatísticas de queda de idosos no Brasil

6.1. Introdução do Capítulo 6

6.2. Pesquisas sobre acidentes residenciais com

150 idosos

6.2.1. Classificação de Queda

150

6.2.2. Cômodo residencial mais perigoso

155

6.3. Conclusão do Capítulo 6

156

6.4. Referências Bibliográficas do Capítulo 6

157

\section{Banheiros Domiciliares}

160

7.1. Introdução do Capítulo 7

160

7.2. Resumo histórico sobre banheiros no Brasil

161

7.3. Legislação vigente na cidade do Rio de Janeiro

164

7.3.1. Código de Edificações do Rio de Janeiro

165

7.3.2. ABNT 9050 Acessibilidade

166

7.4. Sugestões de autores diversos de diretrizes de

172

banheiro residencial para idosos

7.5. Produtos para adaptação de banheiros para

179 idosos, disponíveis no mercado carioca

7.6. Conclusão do Capítulo 7

192

7.7. Referências Bibliográficas do Capítulo 7

194

8. Delineamento da Pesquisa

197

8.1. Introdução do Capítulo 8

197

8.1.1. Contextualização do Problema 202

8.2. Objeto da Pesquisa 204

8.3. Problema/Hipótese 205

8.4. Variáveis 206

8.5. Objetivos 209

8.6. Justificativa 210

8.7. Estado da Arte 211

8.8. Levantamento de Métodos e Técnicas 213 
8.8.1. Metodologia Ergonômica de Anamaria de

Moraes - Apreciação Ergonômica

8.8.2. Estudo de Entrevistas

232

8.8.3. Estudo de Grupo de Foco

239

8.8.4. Estudo de Formulários e Questionários

247

8.9. Conclusão do Capítulo 8

8.10. Referências Bibliográficas do Capítulo 8

\section{Análise dos Resultados}

255

9.1. Dados coletados a partir da realização de

Apreciação Ergonômica de banheiros de idosos:

Análise

9.2. Dados coletados a partir da realização de

332

Entrevistas com idosos: Análise

9.3. Dados coletados a partir da realização de

Entrevistas com médicos geriatras: Análise

9.4. Dados coletados a partir da realização de Grupo 351 de Foco: Análise

9.5. Dados coletados a partir da aplicação dos 363 formulários: Tabulação e Análise

10. Conclusão

379

10.1 Sugestão de Diretrizes para composição de 382 banheiro residencial para idosos 